\title{
Article
}

\section{Child maltreatment in Dubai and the Northern United Arab Emirates: dental hygienists and assistants' knowledge}

\begin{abstract}
Al Hashmi, R., Hussein, I., Kowash, M., Welbury, Richard and AlHalabi, M.

Available at http://clok.uclan.ac.uk/36671/

Al Hashmi, R., Hussein, I., Kowash, M., Welbury, Richard ORCID: 0000-00029322-2440 and Al-Halabi, M. (2021) Child maltreatment in Dubai and the Northern United Arab Emirates: dental hygienists and assistants' knowledge. European Archives of Paediatric Dentistry . ISSN 1818-6300
\end{abstract}

It is advisable to refer to the publisher's version if you intend to cite from the work. http://dx.doi.org/10.1007/s40368-021-00602-9

For more information about UCLan's research in this area go to http://www.uclan.ac.uk/researchgroups/ and search for <name of research Group>.

For information about Research generally at UCLan please go to http://www.uclan.ac.uk/research/

All outputs in CLoK are protected by Intellectual Property Rights law, including Copyright law. Copyright, IPR and Moral Rights for the works on this site are retained by the individual authors and/or other copyright owners. Terms and conditions for use of this material are defined in the policies page.

\section{CLoK}

Central Lancashire online Knowledge www.clok.uclan.ac.uk

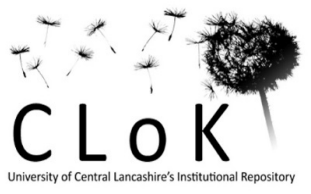




\section{Child maltreatment in Dubai and the Northern United Arab Emirates: dental hygienists and assistants' knowledge}

\section{ABSTRACT}

Purpose: Dental assistants (DAs) and hygienists (DHs) should play an active role in the detection and reporting of child abuse and neglect (CAN). We aimed to investigate CAN knowledge of DAs and DHs in the United Arab Emirates (UAE) and some of the inhibiting factors to the process of CAN reporting.

Methods: A cross sectional study design was utilized. We surveyed 186 DAs and DHs using a previously validated self-administered anonymous CAN knowledge questionnaire. Statistical analysis was performed using $\chi^{2}$-square, Fisher's exact test, ttest/Mann-Whitney, and a ROC curve $(\mathrm{p}<0.05)$.

Results: Among 186 DAs and DHs surveyed, Satisfactory knowledge of CAN was demonstrated by 50.5\%. DAs scored a significantly higher score of knowledge compared to DHs ( $\mathrm{p}=0.03)$. The most reported CAN referral inhibiting factor was "being afraid to get in trouble with parents". The recognition of a child with special needs and parents missing multiple appointments as risk factors for CAN was significantly higher in the DAs compared to DHs [ $\mathrm{p}=0.04, \mathrm{p}=0.024$ respectively]. Awareness of local laws was related to CAN knowledge in DAs $(\mathrm{p}=0.012)$ and DHs $(\mathrm{p}=0.008)$.

Conclusion: the lack of appropriate knowledge regarding CAN necessitates a clear reporting process and better education for DAs and DHs in the UAE.

\section{Key words}

Dental assistants, dental Hygienists, child maltreatment, child abuse, child neglect. 


\section{INTRODUCTION}

In 1985, a manuscript titled "the battered child syndrome" was published by pediatrician Henry Kempe and his colleagues (Kempe et al. 1985). The manuscript drew attention to fractures in children that could only have been caused 'on purpose'. Since that time, awareness of child abuse has increased and is an international concern. Currently, the term "Child Maltreatment" is a well-defined term that is widely known and utilized, and which covers all forms of Child Abuse and Neglect (CAN) (McCoy and Keen 2013).

The International Society for the Prevention of Child Abuse and Neglect compared the definition of CAN from 58 countries and found many similarities (Bross et al. 2002). In 1999, the World Health Organization (WHO) consultation on Child Abuse Prevention released an international definition: "Child abuse or maltreatment constitutes all forms of physical and/or emotional ill-treatment, sexual abuse, neglect or negligent treatment or commercial or other exploitation, resulting in actual or potential harm to the child's health, survival, development or dignity in the context of a relationship of responsibility, trust or power"' (World Health Organization Consultation 1999).

As per Article 273 of the UAE Federal Child Protection Law No. 3 of 2016, individuals are obligated to report suspected cases of child maltreatment to the authorities (United Arab Emirates Government 2016). Article 273 also confirmed that healthcare providers will be penalised for failing to report injuries - particularly those which are suspicious. Furthermore, this law detailed that healthcare providers will be immune from prosecution when they breach patient-client confidentiality whilst reporting something suspicious. Healthcare professionals and any person, who has direct contact with children, should have the ability to identify CAN cases through proper training and continuing educational CAN courses (Balmer et al. 2010). Dental Professionals are often in a position that allows them to detect and recognize CAN because they have regular contact with children and 
their families (Harris et al. 2009). The head and neck region is the main area exposed during the dental examination which makes it easier for the dental team to detect any signs of abuse or neglect causing concern and thus report it. Studies have found that the head and neck region is more frequently affected by CAN injuries (Becker et al. 1978; Fisher-Owens et al. 2017). It was reported that the physical abuse of children manifests in the oro-facial region in 50-77\% of abuse cases (Lee et al. 2012).

Dental assistants and hygienists can play a major role in the detection and reporting of CAN as they are usually the first line of contact with paediatric patients and their parents. In many instances, they spend more time with patients than the dentist (Nuzzolese et al. 2009). Therefore, they should be aware of local child protection procedures including reporting of any suspected incidents (Harris et al. 2009).

Chadwick et al. in 2009 conducted a UK study involving dental therapists (Chadwick et al. 2009). They concluded that dental therapists were reluctant to refer cases of suspected child abuse. Another study by Tilvawala et al. found that most New Zealand dental therapists believed they had an important role to play in child protection (Tilvawala et al. 2014).

A Danish study conducted in 2010 showed that $8.9 \%$ of hygienists were certain about cases which they had reported within the last 6 months compared to only $6.3 \%$ of Dentists (Uldum et al., 2010). Harmer-Beem found evidence that the dental hygienists who attended a continuous development program had a higher self-perceived likelihood to report abuse (Harmer-Beem 2005).

To our knowledge, few studies were found in the literature that investigated the knowledge of dental assistants (nurses) among the rest of the dental healthcare team. The number of dental assistants involved in one study was only three (Harris et al. 2009). This study revealed a significant gap between recognizing signs of abuse and responding 
effectively. A study of dental healthcare providers knowledge regarding CAN in Malaysia included 38 dental nurses among the other participants. The dental nurses were reported to have a range of $48.5 \%-69.7 \%$ of accurate knowledge regarding different aspects of CAN. (Hussein et al. 2016)

The aim of this study was to determine the knowledge of dental assistants and dental hygienists in the UAE regarding child maltreatment, protection, child safeguarding issues and the UAE Child Protection Law. The study also aimed to identify factors that deterred dental assistants and hygienists from referring suspected CAN cases.

\section{METHODS}

This study was a cross-sectional survey with a quantitative, descriptive, and comparative design. Data was collected by a questionnaire from dental assistants and hygienists in Dubai and the Northern Emirates of the UAE in the period between October ${ }^{\text {st }}, 2018$ to March $31^{\text {st }}$, 2019. The questionnaire, conducted in English, was distributed electronically by email and a link to a Survey Monkey ${ }^{\mathrm{TM}}$ survey was shared with randomly selected assistants and hygienists from the list of licensed dental assistants and hygienists in Dubai and the Northern Emirates of the UAE. The participants were chosen by a softwaregenerated random list (Urbaniak and Plous, 2013).

Randomly chosen $25 \%$ of these registered dental assistants and hygienists were sent the questionnaires by email. The total number of registered dental assistants and hygienists at the time of the study conduction was 1208 . The target number of returned surveys was about $10 \%$ of the population of dental assistants and hygienists (121) (Barlett, Kotrlik et al. 2001).

Ethical approval to conduct the survey was obtained from the Research and Ethics Committee of the Hamdan Bin Mohammed College of Dental Medicine (HBMCDM)/ 
Mohamed Bin Rashid University of Medicine and Health Sciences (MBRU) Research and Ethics Committee (Reference Number NF-H-13-02-11).

The questionnaire was adopted from a previous study by Cairns et al (Cairns et al. 2005). Permission to use the questionnaire with UAE modifications to suite the local culture and societal make up was obtained. The questionnaire responses were completely anonymous.

Prior to the survey, a pilot study was conducted among 10 dental assistants and hygienists and a few modifications were incorporated in the order of the questions and their clarity. These surveys were not included in the final analysis.

The questionnaire consisted of 12 questions which examined the knowledge and awareness levels of the participants regarding CAN related issues. The questions were divided into four categories: demographic; education/awareness; practice related; and knowledge questions.

In the fourth category (knowledge questions), the ideal answers were determined by a consensus from three experienced paediatric dentistry consultants in the UAE.

An overall score of correct answers to the knowledge questions was calculated with a maximum score of 11. This score was called the 'Score of Knowledge' and it allowed quantification of the knowledge of the participants in CAN related matters.

Data was entered into a database using SPSS for windows version 23.0 (SPSS Inc., Chicago, IL). Results were cross tabulated to examine the independency between variables. Statistical analysis was performed using $\chi^{2}$ for test of association and Fisher's exact test as appropriate. Where two or more continuous independent variables were examined, t-test/Mann-Whitney was used to compare means of two groups. A receiver operating characteristic (ROC) curve was used to determine the cut-off point of satisfaction of knowledge. Frequency tables' bar and lines graphs were performed for 
descriptive statistics. A p-value of less than 0.05 was considered significant in all statistical analysis.

\section{RESULTS}

\section{Study sample characteristics}

The final number of sent surveys was 300 surveys and the completed surveys was 186

(137 dental assistants and 49 hygienists) resulting in a response rate of $62 \%$. The demographic characteristics of the 186 dental assistants and dental hygienists who participated in the study are summarized in Table 1.

\begin{tabular}{|c|c|c|c|}
\hline & & $\begin{array}{c}\text { Dental } \\
\text { Assistants } \\
\mathrm{n}(\%)\end{array}$ & $\begin{array}{c}\text { Dental } \\
\text { Hygienists } \\
\mathrm{n}(\%)\end{array}$ \\
\hline Total number & & 137 & 49 \\
\hline \multirow{2}{*}{ Gender } & Male & $27(19.7 \%)$ & $11(22.4 \%)$ \\
\hline & Female & $110(80.3 \%)$ & $38(77.6 \%)$ \\
\hline \multirow{3}{*}{ Age } & $20-30$ & $53(38.7 \%)$ & $16(32.7 \%)$ \\
\hline & $31-40$ & $59(43.1 \%)$ & $25(51 \%)$ \\
\hline & $\geq 41$ & $25(18.2 \%)$ & $8(16.3 \%)$ \\
\hline \multirow{4}{*}{ Country of Education } & UAE & $5(3.6 \%)$ & $4(8.2 \%)$ \\
\hline & India & $36(26.3 \%)$ & $12(24.5 \%)$ \\
\hline & Philippine & $80(58.4 \%)$ & $16(32.7 \%)$ \\
\hline & Others & $16(11.7 \%)$ & $17(34.7 \%)$ \\
\hline \multirow{3}{*}{ Type of Practice } & Private & $54(39.4 \%)$ & $29(59.1 \%)$ \\
\hline & Governmental & $71(51.8 \%)$ & $16(32.7 \%)$ \\
\hline & Institute & $12(8.8 \%)$ & $4(8.2 \%)$ \\
\hline
\end{tabular}

Table 1. Demographic characteristics of the study sample. 


\section{Score of knowledge}

The overall score of knowledge was measured using questions 11 and 12 of the questionnaire with a maximum score of 11 . Dental assistants scored significantly higher $(7.75( \pm 1.81))$ compared with dental hygienists $(7.20( \pm 1.5))(\mathrm{p}=0.03)$. The combined score of knowledge for all study participants was $7.61( \pm 1.73)$. Figure 1 demonstrates these results using the Mann-Whitney U test.

\section{Aspects of CAN knowledge}

The aspects of CAN knowledge used to calculate the overall score of knowledge are presented in Table 2. The knowledge was evaluated by both the ability to identify known CAN risk factors and to differentiate between incidents of abuse and neglect.

It is noteworthy to mention that a statistically significant difference was found between the dental assistants and hygienists when identifying special needs as a risk factor for CAN ( $\mathrm{p}=0.040)$ and when recognising missing multiple scheduled dental appointments as a risk factor for neglect $(\mathrm{p}=0.024)$.

\begin{tabular}{|l|c|c|c|c|}
\hline & Correct answer & $\begin{array}{c}\text { Correct answer/ } \\
\text { Dental Assistant } \\
(\%)\end{array}$ & $\begin{array}{r}\text { Correct } \\
\text { answer/Dental } \\
\text { hygienist (\%) }\end{array}$ & P-value \\
\hline CAN risk factors & yes & $118(88.1 \%)$ & $41(83.7 \%)$ & 0.291 \\
\hline Young age of the child & yes & $93(69.4 \%)$ & $38(77.6 \%)$ & 0.186 \\
\hline Poor neighbourhood & yes & $111(82.8 \%)$ & $34(69.4 \%)$ & $0.04^{*}$ \\
\hline Child with special needs & yes & $79(59 \%)$ & $24(49 \%)$ & 0.150 \\
\hline Single mother & yes & $96(71.6 \%)$ & $29(59.2 \%)$ & 0.078 \\
\hline $\begin{array}{l}\text { Low income family } \\
\text { History of parental drug } \\
\text { or alcohol abuse }\end{array}$ & yes & $125(93.3 \%)$ & $48(98 \%)$ & 0.199 \\
\hline
\end{tabular}




\begin{tabular}{|l|l|l|l|l|}
\hline \multicolumn{4}{|l|}{ Identification of type of CAN } \\
\hline $\begin{array}{l}\text { A 5-year-old child left in } \\
\text { a shopping mall }\end{array}$ & neglect & $118(88.1 \%)$ & $43(87.8 \%)$ & 0.567 \\
\hline $\begin{array}{l}\text { Mother doesn't attend to } \\
\text { her child's overall } \\
\text { hygiene and appearance }\end{array}$ & neglect & $112(83.6 \%)$ & $35(71.4 \%)$ & 0.055 \\
\hline $\begin{array}{l}\text { Parents that miss } \\
\text { multiple-scheduled visits }\end{array}$ & neglect & $103(77.4 \%)$ & $30(61.2 \%)$ & $0.024^{*}$ \\
\hline $\begin{array}{l}\text { Parents that verbally } \\
\text { humiliate their child for } \\
\text { not opening their mouth } \\
\text { during dental treatment }\end{array}$ & abuse & $82(61.2 \%)$ & $29(59.2 \%)$ & 0.468 \\
\hline $\begin{array}{l}\text { A child attends with } \\
\text { bruises over bony } \\
\text { prominences }\end{array}$ & none & $1(0.7 \%)$ & $2(4.1 \%)$ & 0.175 \\
\hline
\end{tabular}

*statistically significant

Table 2. Comparison of aspects of knowledge of CAN between dental assistants and hygienists.

\section{Aspects of previous education and awareness}

The previous sources of CAN knowledge for the participants are detailed in Table 3.

There was no statistically significant difference between the groups when it came to the prior knowledge as well as the sources of knowledge.

\begin{tabular}{|l|c|c|c|}
\hline Aspects of education & $\begin{array}{l}\text { Dental } \\
\text { assistants } \\
\text { (Yes\%) }\end{array}$ & $\begin{array}{l}\text { Dental } \\
\text { hygienists } \\
\text { (Yes\%) }\end{array}$ & P value \\
\hline $\begin{array}{l}\text { Were Child Abuse/Protection } \\
\text { lectures or seminars part of } \\
\text { your formal undergraduate } \\
\text { program? }\end{array}$ & $78(58.2)$ & $31(63.3)$ & 0.329 \\
\hline $\begin{array}{l}\text { Have you attended any } \\
\text { continuing education lectures } \\
\text { or seminars on (Barlett, } \\
\text { Kotrlik et al. 2001)Child } \\
\text { Abuse/Protection? }\end{array}$ & $32(24.1)$ & $18(36.7)$ & 0.067 \\
\hline $\begin{array}{l}\text { Do you feel you need further } \\
\text { training in child abuse } \\
\text { recognition? }\end{array}$ & $122(90.4)$ & $47(95.9)$ & 0.183 \\
\hline $\begin{array}{l}\text { Are you aware of the UAE } \\
\text { child protection law and } \\
\text { guidelines? }\end{array}$ & $24(40)$ & $25(51)$ & 0.122 \\
\hline
\end{tabular}

Table 3. Aspects of education and awareness of the participants. 


\section{Different authorities to whom participants reported CAN}

When asked about different authorities the participants had reported CAN to in the past, $92 \%$ of the hygienists had reported to their supervisors, $8 \%$ to the police with no one reported to the official child protection authorities. On the other hand, dental assistants reported equally (33\%) to their supervisors, police and the official child protection authorities.

\section{Child protection referral inhibiting factors}

The participants were asked if a certain factor affected their decision to make a referral in cases of suspected child abuse. The factor receiving the highest percentage was 'being afraid to get in trouble with the parents (49.1\%). The distribution of these factors is shown in Figure 2

\section{Level of knowledge}

To determine the participants' satisfactory level of knowledge, a receiver operating characteristic (ROC) curve was utilized. The percentage of participants in the study who demonstrated satisfactory child protection knowledge was $50.5 \%$, with dental assistants scoring higher compared to dental hygienists.

\section{Association between previous education/awareness and level of knowledge}

When cross tabulating the questions regarding previous education/awareness and the level of knowledge among dental assistants and hygienists, a significant relationship was found between the awareness of the UAE child protection laws and guidelines and having a satisfactory level of knowledge $(\mathrm{p}=0.012,0.008)$ respectively.

\section{DISCUSSION}

This study was conducted to assess the knowledge of dental assistants and hygienists about CAN in the UAE. While several studies have investigated the knowledge of hygienists and dentists about CAN globally, (Al Hajeri et al. 2018; Al-Amad et al. 2016; 
Kilpatrick et al. 2001) very little international information exists regarding CAN knowledge within the dental assistant group. Albeit dentistry and CAN in the UAE has been studied, before (Al-Amad et al. 2016) and after (Al Hajeri et al. 2018) the issuance of the child protection law in 2016, no information is available regarding CAN knowledge of dental assistants and hygienists in the UAE.

We attempted to quantify the knowledge of our study participants by calculating a knowledge score for each of them. We found that the dental assistants possessed significantly better knowledge in CAN compared to the dental hygienists. A possible explanation by the authors for this is the way the work force market operates in the UAE. It is not uncommon for medical nurses to work as dental assistants. These medical nurses probably possess better background information regarding CAN compared to hygienists. Medical nurses have been reported to play a major role in recognition of child abuse and neglect cases. (Caneira and Myrick 2015)

The participants in this study had a lower score of knowledge compared to dentists in a recently conducted UAE study (Al Hajeri et al. 2018) even though a higher percentage of the present study's participants reported CAN lectures as part of their undergraduate studies.

Dental assistants in our study identified that a "child with special needs" was at a higher risk of CAN significantly more compared to the hygienists. This might be explained by the fact that dental assistants are working closely with dentists who are more likely to treat children with special needs than hygienists and hence they are more aware of the vulnerabilities of this population of patients. Furthermore, as highlighted above, in the UAE, many dental assistants have medical nursing qualifications which might have given them more exposure to children with special needs than hygienists. Overall, $78 \%$ of our study population agreed with the fact that a special needs child is at increased risk to 
CAN. In a study in Malaysia, $57.9 \%$ of the participating dental nurses reported the child being disabled as a risk factor for child abuse (Hussein et al. 2016). Additionally, AlDabaan et al. in 2014 reported that $76.2 \%$ of the dentists living in the Kingdom of Saudi Arabia (KSA) considered a child with a disability as a risk factor for CAN. (Al-Dabban et al. 2014)

The issue of parents missing multiple scheduled visits in relation to CAN was also investigated. The current study found that $71.5 \%$ of the participants considered repeatedly missing appointments as a manifestation of neglect, mirroring the findings of Al Hajeri et al. (Al Hajeri et al. 2018); as $70.6 \%$ of their dentists study population reported the same. Dental assistants recognized this issue as a manifestation of neglect significantly more than the hygienists.

Most of our study's participants had CAN training in their undergraduate programs, yet they felt the need for further training. These results are like a previous study conducted in the UAE to measure the dentists' knowledge of CAN. Al Hajeri et al. reported that $58 \%$ of the UAE dentists had undergraduate CAN training (Al Hajeri et al. 2018). Continuing education development programs where reported to be the highest source of knowledge regarding CAN among dental nurses in Malaysia (Hussein et al. 2016).

The UAE child protection law is a relatively new law that was published in 2016 (United Arab Emirates Government, 2016). Consequently, 60\% of dental assistants and $49 \%$ of hygienists in our study reported unfamiliarity with the law. A suggestion to make the knowledge of the UAE child protection law a compulsory aspect before obtaining a professional license in the UAE is proposed, to increase such essential knowledge. This aspect had been practiced by authorities in other countries, such as the General Dental Council of the UK which mandates that dental care professionals should be aware of child protection laws and guidelines. (General Dental Council 2005) Our study's participants 
had higher knowledge of the local law when compared to a similar study conducted in the UAE which showed that a lower rate of $46.5 \%$ of dentists participants were aware of the guidelines. (Al Hajeri et al. 2018). This might be explained by the fact that more time has passed since the law had been enacted for the current study's participants to have more knowledge about it compared to the participants in the Al Hajeri et al. study.

The results of our study revealed that the participants used different ways of reporting CAN cases. Dental hygienists reported more cases to their supervisors compared to dental assistants. Hygienists might feel more independent and confidents to bring issues up including CAN related concerns to their supervisors compared to assistants who might feel a bit intimidated by the fact that their interactions with the patients are dependent on the dentists much more than the hygienists. This situation was somewhat similar to two other studies; a Danish one (Uldum et al. 2010) where $>90 \%$, and a Croatian one (Cukovic-Bagic et al. 2015) where $86.3 \%$ of the hygienists' first choice was to share their concerns with supervisors or colleagues. In their Danish study, Uldum et al. reported that $70 \%$ of participants chose reporting to social services (which is equivalent in the UAE to the official abuse authorities) (Uldum et al. 2010), this was much higher than the $33 \%$ of participants that reported the same in the present study. One method of reporting the CAN cases is to report to parents (caregiver), many participants in previous studies had chosen this option (Uldum et al. 2010; Cukovic-Bagic et al. 2015; Al-Amad et al. 2016). In contrast, no one in our study chose "informing the parents" upon suspicion of a CAN case. Hussein et al. reported that $47.4 \%$ of the participating dental nurses reported to the Social department/family protection department (Hussein et al. 2016). It is worth mentioning here that the reporting process for the recent child protection law in the UAE is still a work in progress. 
Many factors can jeopardize professional judgment of the dental team during the referral processes. In our study, we considered different factors that can affect the decision to refer. The most chosen factor by the participants (49\%) was being afraid to get in trouble with the parents. This was comparatively a lower percentage than the $88 \%$ reported in a Saudi study (Al Dabban et al. 2014) but higher than one UAE dentists' study (Al-Amad et al. 2016). A recent study in the UAE reported that $37.7 \%$ of the participating dentists chose fear of family violence to dentist as an inhibiting factor for reporting CAN (Al Hajeri et al. 2018). The fact that the participants in the current study saw fear of family violence as more of an inhibiting factor compared to the UAE dentists surveyed in the 2 mentioned studies (Al-Amad et al. 2016; Al Hajeri et al. 2018) might be explained by the professional hierarchy in the dental clinics setting. The dentists, as leaders of the team in the clinic, might feel less vulnerable from parental violence as opposed to assistants and hygienists.

Another possible referral inhibiting factor is being unaware of whom to report to. In the current study, $43 \%$ of the participant's chose this reason as a barrier to making a referral. In a Danish hygienists' study, the same factor was reported to be a barrier by $63 \%$ of the participants (Uldum et al. 2010) and by $60.2 \%$ of participants in a UAE dentists' study (Al Hajeri et al. 2018) To emphasize the point mentioned previously; the recently published UAE child protection law needs a proper mechanism in place for the referral process to be implemented. This could also support the dental team to report without concerns or fears from the child's parents or caregivers.

One factor which was strongly associated with the aim of this study was "being afraid of the wrong diagnosis". Of the study participants, $32 \%$ reported this factor as a deterrent to reporting. Surprisingly, and despite the reported knowledge gap in the current study's participants, this inhibiting factor was less reported compared to other studies. This same 
factor was reported by $48 \%$ of the participants in a Croatian study (Cukovic-Bagic et al. 2015), compared to $79 \%$ of hygienists in a Danish study (Uldum et al. 2010) and 78\% of dentists and dental care professionals with an interest in paediatric dentistry participating in a UK study. (Harris et al. 2009) Lack of proper training for the dental team regarding CAN affects their capabilities to recognize CAN cases and makes them more uncertain of the diagnosis of CAN in children at risk. (Azevedo et al. 2012)

One of the unique findings in our study was that $23 \%$ of the dental assistants and hygienists were afraid that the dentist they are working with will not accept their concerns about CAN. This might stem, as mentioned previously, from the hierarchical structure of the dental clinic which gives the dentists a presumed higher authority over other staff and might lead to the dental team only reporting cases they are very sure about and only after approval by the dentist.

Previous education can play a major role in the enrichment of the knowledge of health professional' including the dental team members. (Silva-Oliveira et al. 2019)

Although the number of assistants participating in the study compared to the number of hygienists reflected the ratio of assistants to hygienists in the UAE, it might have resulted in some statistical inaccuracies when comparing the results of the two groups.

The limitations of the present study are summarised in this paragraph. Due to issues of access, we were unable to include the assistants and hygienists in the Emirate of Abu Dhabi in our study. Including them might have provided a better representation of the CAN knowledge dental assistants and hygienists in the entire UAE. Additionally and although we postulated that some of the differences in knowledge between dental assistants and hygienists were due to possible medical training of the assistants, we were unable to verify that as the survey did not ask about the degree of the participants. 
The results of the present study indicate the need to make the knowledge of the UAE child protection law and the reporting process a compulsory aspect before obtaining a professional license. Furthermore, the introduction of regular CAN continuous professional development might improve and encourage the dental assistants and hygienists to recognize and report CAN cases.

\section{CONCLUSIONS:}

- The percentage of participants with satisfactory CAN knowledge was 50.5\%, with dental assistants scoring significantly higher compared to hygienists.

- The recognition of "a child with special needs" as a risk factor for CAN, and consideration of "parents missing multiple scheduled appointments as child neglect" was significantly higher in the dental assistants' group compared to the hygienists.

- The most common inhibiting referral factor for CAN cases reported by the participants was "being afraid to get in trouble with parents".

- Awareness of the UAE local child protection guidelines and laws was statistically related to the CAN knowledge level both in the dental assistants and hygienists' groups.

\section{REFERENCES}

Al Hajeri H, Al Halabi M, Kowash M, Khamis AH, Welbury R, Hussein I. Assessment of the knowledge of United Arab Emirates dentists of Child Maltreatment, protection and safeguarding. Eur J Paediatr Dent. 2018;19(2):105-18.

Al-Amad SH, Awad MA, Al-Farsi LH, Elkhaled RH. Reporting child abuse cases by dentists working in the United Arab Emirates (UAE). J Forensic Leg Med. 2016;40:125 . 
Al-Dabaan R, Newton JT, Asimakopoulou K. Knowledge, attitudes, and experience of dentists living in Saudi Arabia toward child abuse and neglect. Saudi Dent J. 2014;26(3):79-87.

Azevedo MS, Goettems ML, Brito A, Possebon AP, Domingues J, Demarco FF, Torriani DD. Child maltreatment: a survey of dentists in southern Brazil. Braz Oral Res. 2012;26(1):5-11.

Balmer R, Gibson E, Harris J. Understanding child neglect. Current perspectives in dentistry. Prim Dent J. 2010;17(3):105-9.

Barlett J, Kotrlik, J, Higgins C. Organizational Research: Determining Appropriate Sample Size in Survey Research. Information Technology, Learning, and Performance Journal 2001;19(1):43-50

Becker DB, Needleman HL, Kotelchuck M. Child abuse and dentistry: orofacial trauma and its recognition by dentists. J. Am. Dent. Assoc. 1978;97(1):24-8.

Bross DC, Miyoshi TJ, Miyoshi PK, Krugman RD, Kempe Children's Ctr, Dept of Pediatrics. World perspectives on child abuse: The fifth international resource book. Denver (CO): The International Society for the Prevention of Child Abuse and Neglect (ISPCAN) and the Kempe Children's Center, University of Colorado School of Medicine. 2002:103-5.

Cairns AM, Mok JY, Welbury RR. The dental practitioner and child protection in Scotland. Br Dent J 2005;199(8):517-20.

Caneira L, Myrick KM. Diagnosing Child Abuse: The Role of the Nurse Practitioner. J Nurse Pract. 2015;11(6):640-6.

Chadwick BL, Davies J, Bhatia SK, Rooney C, McCusker N. Child protection: training 
and experiences of dental therapists. Br. Dent. J. 2009;207(3):E6; discussion 130-1.

Cukovic-Bagic I et al. Croatian dentists' knowledge, experience, and attitudes in regard to child abuse and neglect. Int J Paediatr Dent. 2015;25(6):444-50.

Fisher-Owens SA, Lukefahr JL, Tate AR. Oral and Dental Aspects of Child Abuse and Neglect. Pediatr Dent. 2017;39(4):278-283.

General Dental Council, Great Britain. Standards for dental professionals.; 2005. https://www.gdc-uk.org/ (Last accessed 20 May 2020).

Harmer-Beem M. The perceived likelihood of dental hygienists to report abuse before and after a training program. J Am Dent Hyg Assoc. 2005 1;79(1):7

Harris JC, Elcock C, Sidebotham PD, Welbury RR. Safeguarding children in dentistry: 1. Child protection training, experience and practice of dental professionals with an interest in paediatric dentistry. Br Dent J 2009;206(8):409.

Hussein AS, Ahmad R, Ibrahim N, Yusoff A, Ahmad D. Dental health care providers' views on child physical abuse in Malaysia. Eur Arch Paediatr Dent. 2016;17(5):387-395.

Kempe CH, Silverman FN, Steele BF, Droegemueller W, Silver HK. The battered-child syndrome. Child Abuse Negl. 1985;9(2):143-54.

Kilpatrick NM, J. Scott J, Robinson S. Child protection: a survey of experience and knowledge within the dental profession of New South Wales, Australia. Int J Paediatr Dent. 2001;9(3):153-9

Lee JJ, Gonzalez-Izquierdo A, Gilbert R. Risk of maltreatment-related injury: A crosssectional study of children under five years old admitted to hospital with a head or neck injury or fracture. PLoS One. 2012;7(10):1-10.

McCoy ML, Keen SM. Child abuse and neglect. Psychology Press. Hove, United Kingdom 2013 pp. 3-22. 
Nuzzolese E, Lepore M, Montagna F, et al. Child abuse and dental neglect: the dental team's role in identification and prevention. Int J Dent Hyg. 2009;7(2):96-101.

Silva-Oliveira, F, Andrade, CI, Guimarães, MO, Ferreira, RC, Ferreira, EF, Zarzar, PM. Recognition of child physical abuse by a group of Brazilian primary care health professionals. Int J Paediatr Dent. 2019; 29: 624-34.

Tilvawala D, Murray C, Farah R, Broadbent JM. New Zealand dental therapists' beliefs regarding child maltreatment. Aust N Z J Public Health. 2014;38(5):480-4.

Uldum B, Christensen HN, Welbury R, Poulsen S. Danish dentists' and dental hygienists' knowledge of and experience with suspicion of child abuse or neglect. Int J Paediatr Dent. 2010;20(5):361-5.

United Arab Emirates Goverment. UAE Child Protection Law. No.3 (2016) Official Gazette No. 593:53.

Urbaniak, G. C., \& Plous, S. (2013). Research Randomizer (Version 4.0) (Computer software). Retrieved on February 15, 2018, from http://www.randomizer.org/

World Health Organization Consultation on Child Abuse Prevention. Report of the Consultation on Child Abuse Prevention, 29-31 March 1999, WHO, Geneva. 1999. 
List of Figures:

Figure 1. Comparison of the score of knowledge between dental assistants and hygienists.

Figure 2. Distribution of child protection referral inhibiting factors.

Barlett, J. E., et al. (2001). "Organizational Research: Determining Appropriate Sample Size in Survey Research." Information Technology, Learning, and Performance Journal 19. 